\title{
PERKEMBANGAN KEHIDUPAN EKONOMI MASYARAKAT KAMPUNG TUA TANJUNG PIAYU LAUT SEBAGAI TEMPAT WISATA KULINER DI KOTA BATAM
}

\section{DEVELOPMENT OF THE ECONOMIC OF LIFE OF THE COMMUNITY OLD VILLAGE TANJUNG PIAYU LAUT AS A CULINARY ATRACTION IN THE CITY OF BATAM}

\author{
Ridho Fernando ${ }^{1}$, Arnesih ${ }^{2}$ \\ ${ }^{1}$ (ProdiPendidikan Sejarah, Fakultas Fkip, Universitas Riau Kepulauan, Indonesia) \\ ${ }^{2}$ (Prodi Pendidkan Sejarah, Fakultas Fkip Universitas Riau Kepulauan, Indonesia) \\ ${ }^{1}$ ridhofernando@gmail.com , ${ }^{2}$ arnesih@fkip.unrika.ac.id
}

\begin{abstract}
Abstrak
Perkembangan kehidupan ekonomi masyarakat Kampung Tua Tanjung Piayu Laut sebagai tempat wisata kuliner di Kota Batam tahun 2010-2016, merupakan salah satu wujud mengangkat kearipan lokal Batam khususnya mengenai Kampung Tua Tanjung Piayu Laut yang merupakan salah satu kampung tua di Kota Batam. Penelitian ini bertujuan mengetahui perkembangan kehidupan ekonomi masyarakat Kampung Tua Tanjung Piayu Laut sebagai tempat wisata kuliner di Kota Batam tahun 2010-2016. Jenis penelitian ini adalah penelitian kualitatif dengan pendekatan ilmu sosial dan ekonomi. Metode dalam penelitian ini menggunakan metode historis dengan 4 tahapan yaitu: 1. Heuristik 2. Kritik Sumber 3. Interpretasi 4. Historiografi. Hasil penelitian ini menunjukan adanya perkembangan kehidupan ekonomi masyarakat Kampung Tua Tanjung Piayu Laut sebagai tempat wisata kuliner di Kota Batam tahun 2010-2016. Perkembangan yang terjadi pada kehidupan masyarakat Kampung Tua Tanjung Piayu Laut yaitu: semakin berkembangannya pendidikan masyarakat sehingga berpengaruh terhadap mata pencaharian mereka. Perkembangan ekonomi masyarakat Kampung Tua Tanjung Piayu Laut seperti mata pencaharian dan pendapatan sudah beranekaragam. Masyarakat tidak hanya bekerja sebagai nelayan saja, ada juga yang sudah bekerja di darat seperti bekerja di perusahaan dan bekerja di rumah makan seafood. Dengan demikian semakin meningkat kesejahteraan masyarakat Kampung Tua Tanjung Piayu Laut.
\end{abstract}

Kata Kunci: Kehidupan Ekonomi, Kampung Tua Tanjung Piayu Laut, Wisata Kuliner

\begin{abstract}
The development of economic life of Kampung Tua Tanjung Piayu Laut community as a place of culinary tourism in Batam City in 2010-2016. It is one of the forms to lift the local history of Batam, especially about the Old Village Tanjung Piayu Laut which is one of the old villages in the city of Batam. This study aims to determine the economic life of Kampung Tua Tanjung Piayu Laut community as a culinary place in Batam city in 2010-2016. This type of research is a qualitative research with social and economic science approach. Methods in this study using the historical method with 4 stages are: 1. Heuristik 2. Source Criticism 3. Interpretation 4. Historiography. The results of this study show the development of economic life of Kampung Tua Tanjung Piayu Laut community as a place of culinary tourism in the city of Batam in 2010-2016. The development that occurred in the life of Kampung Tua Tanjung Piayu Laut community: the development of education so as to affect their livelihood. Economic development of Kampung Tua Tanjung Piayu Laut community such as livelihoods and income has been diverse. Society not only work as fisherman only, there are also who have worked on land like work in company and work at seafood restaurant. Thus increasing the welfare of Kampung Tua Tanjung Piayu Laut community.
\end{abstract}

Keywords : Economic life, Kampung Tua Tanjung Piayu Laut, CulinaryTour 


\section{PENDAHULUAN}

Pada awal abad ke 20 Kota Batam menjadi daerah dengan potensi ekonomi yang menjanjikan semakin menjadi nyata, dimulai dengan perkembangan perindustrian, perdagangan dan pembangunan infrastruktur Singapura yang dibuka Inggris pada tahun 1819. Sejumlah pengusaha dari Bandar Baru yang sedang berkembang dengan pesatnya itu mulai menanamkan modal dan membuka sejumah usaha di Kota Batam dan pulau-pulau sekitarnya (Dahlan, 2014: 43).

Seiring dengan peresmian prasarana utama pada akhir tahun 1983, kota menjelma menjadi salah satu kota industri baru di wilayah barat Indonesia yang menjanjikan. Salah satu wujud nyata keberhasilan pembangunan di Kota Batam antara lain mega proyek jalan transbarelang sepanjang 54 kilometer, melewati 6 jembatan dengan panjang keseluruhan $2.264 \mathrm{~km}$. Peran transbarelang otomatis menghidupkan kawasan tersebut dan pulau-pulau sekitarnya (Sutrisno, 2007: 88).

Sektor pariwisata dapat dijadikan sebagai salah satu upaya dalam meningkatkan pendapatan daerah Kota Batam. Keberhasilan pengembangan pariwisata menghasilkan peningkatan aliran devisa ke dalam negeri dan dapat memperkuat mata uang rupiah serta menciptakan kegiatan ekonomi lanjutan seperti pengembangan hotel, restoran dan tempat wisata lainnya baik itu kuliner, pantai dan daerah lain yang berpotensi sebagai tempat wisata, yang mampu menciptakan lapangan kerja, peningkatan daya beli baru, pengembangan sarana dan prasarana fasilitas umum.

Kampung Tua Tanjung Piayu Laut merupakan salah satu Kampung Tua yang ada di Kota Batam yang mempunyai kekayaan alam yang sangat besar sehingga banyak sekali terdapat objek wisata alam, budaya maupun sejarah. Pada saat sebelum adanya seafood mata pencaharian masyarakat Kampung Tua Tanjung Piayu Laut masih sangat tradisional, dimana masih mengandalkan laut sebagai mata pencaharian. Teknologi atau alat yang digunakan saat menangkap ikan di laut masih menggunakan alat pancing. Dengan makin maju atau berkembangannya kehidupan masyarakat, teknologi yang digunakan makin 
berkembang, seperti alat yang dulunya pancing sekarang sudah menggunakan teknologi yang modern seperti kapal motor dan jala ikan yang modern.

Berdasarkan dari uraian di atas, penulis bermaksud untuk mengadakan penelitian yang berjudul "Perkembangan Kehidupan Ekonomi Masyarakat Kampung Tua Tanjung Piayu Laut Sebagai Tempat Wisata Kuliner di Kota Batam Tahun 2010-2016".

Menurut Rostow (dalam Supardan, 2008: 417), perkembangan ekonomi suatu masyarakat meliputi lima tahap perkembangan, yaitu tahap masyarakat tradisional, tahap prakondisi tinggal landas, tahap tinggal landas, tahap kematangan (maturity), tahap konsumsi masa tinggi atau besar-besaran.

Sumardi (dalam Basrowi, 2010: 61) kondisi sosial ekonomi adalah suatu kedudukan yang diatur secara sosial dan menempatkan seseorang pada posisi tertentu dalam masyarakat, pemberian posisi itu disertai pula dengan seperangkat hak dan kewajiban yang harus dimainkan oleh si pembawa status. Sastropradja (dalam Basrowi, 2010: 61) kondisi sosial ekonomi adalah keadaan atau kedudukan seseorang dalam masyarakat sekelilingnya. Malo (dalam Basrowi, 2010: 62) kondisi sosial ekonomi merupakan suatu kedudukan yang diatur secara sosial dan menempatkan seseorang pada posisi tertentu dalam sosial masyarakat. Pemberian posisi disertai pula dengan seperangkat hak dan kewajiban yang harus dimainkan oleh si pembawa status.

\section{METODOLOGI PENELITIAN}

Jenis penelitian yang digunakan dalam penelitian ini adalah penelitian kualitatif dengan pendekatan ilmu sosial dan ekonomi. Penelitian kualitatif adalah pengumpulan data pada suatu latar alamiah, dengan menggunakan metode alamiah dan dilakukan oleh orang atau peneliti yang tertarik secara alamiah. Waktu dan pelaksanaan penelitian ini berlangsung dalam kurun waktu bulan April sampai Juni 2017. Tempat penelitian bertempat di Kampung Tua Tanjung Piayu Laut, Kelurahan Tanjung Piayu, Kecamatan Sungai Beduk, Kota Batam, Propinsi Kepulauan Riau. 
Metode dalam penelitian ini menggunakan metode historis. Metode sejarah dapat diartikan sebagai penelitian dan penulisan sejarah dengan menggunakan cara, prosedur atau teknik yang sistematik sesuai dengan asas-asas dan atauran ilmu sejarah. Adapun langkah-langkah dalam penelitian ini adalah heuristik, kritik sumber, interpretasi, dan historiografi (Daliman, 2012: 27).

Heuristik adalah tahapan awal dalam penelitian sejarah. Tahapan awal dalam penelitian sejarah menghimpun sumber-sumber informasi jejak masa lampau. Kritik adalah tahapan selanjutnya setelah heuristik. Tahapan kritik menentukan kebenaran, keotentikan, dan kreadibilitas sumber data. Kritik dibagi menjadi dua yaitu kritik ekstern dan kritik intern. Interpretasi adalah suatu proses penelaahan, penganalisaan, dan penafsiran terhadap data-data yang diteliti. Penulisan sejarah menjadi sarana mengomunikasikan hasil-hasil penelitian yang diungkap, di uji (verifikasi) dan diinterpretasi.

\section{HASIL PENELITIAN DAN PEMBAHASAN}

\section{A. Lokasi Penelitian}

\section{Letak geografis Kota Batam}

Kota Batam merupakan salah satu pulau yang berada di antara perairan Selat Malaka dan Singapura. Tidak ada literature yang dapat menjadi rujukan dari mana nama Batam itu, yang jelas Pulau Batam merupakan sebuah pulau besar dari 329 pulau yang ada diwilayah Kota Batam. Sumber yang dengan jelas menyebutkan nama Batam dan masih dapat dijumpai sampai saat ini adalah Traktat London tahun 1824 (Yakub, 2015: 58).

\section{Kampung Tua Tanjung Piayu Laut}

Kampung Tua Tanjung Piayu Laut terletak di Kelurahan Tanjung Piayu yang berpusat di Pancur dan merupakan bagian dari Kecamatan Sungai Beduk. Kampung Tua Tanjung Piayu Laut termasuk salah satu Kampung Tua di Kota Batam yang memiliki catatan historis panjang. Tempo dulu Kampung Tua Tanjung Piayu Laut ini merupakan tempat laluan bagi Sultan Sulaeman Ibnu Jawi Ibnu Sultan Abdul Rahman yang menyamar menjadi rakyat biasa. 
Historia: Jurnal Program Studi Pendidikan Sejarah

Vol. 3 No. 2 (2018): 92-101

P-ISSN 2301-8305

E- ISSN 2599-0063

Tabel 1. Jumlah kepala keluarga Kampung Tua Tanjung Piayu Laut

\begin{tabular}{|c|c|c|}
\hline No & RT & Jumlah Kepala Keluarga \\
\hline 1 & RT 01 & 92 \\
\hline 2 & RT 02 & 43 \\
\hline \multicolumn{2}{|c|}{ Total } & 135 \\
\hline
\end{tabular}

Tabel 2. Jumlah rumah makan seafood Kampung Tua Tanjung Piayu Laut

\begin{tabular}{|c|c|c|}
\hline No & Rumah Makan & Jumlah \\
\hline 1 & Jawa Melayu & 1 \\
\hline 2 & Mak Uteh & 1 \\
\hline 3 & Love Seafood & 1 \\
\hline 4 & Kelong 777 & 1 \\
\hline 5 & Pantai biru sehati & 1 \\
\hline 6 & We are brothers & 6 \\
\hline
\end{tabular}

Tabel 3. Pendidikan masyarakat Kampung Tua Tanjung Piayu Laut

\begin{tabular}{|c|c|c|c|c|}
\hline Tahun & SD & SMP & SMA/SMK & KULIAH \\
\hline 2010 & 26 & 21 & 15 & 3 \\
\hline 2011 & 28 & 23 & 17 & 4 \\
\hline 2012 & 29 & 25 & 18 & 6 \\
\hline 2013 & 37 & 29 & 24 & 6 \\
\hline 2014 & 39 & 31 & 32 & 9 \\
\hline 2015 & 42 & 34 & 39 & 12 \\
\hline 2016 & 45 & 39 & 41 & 16 \\
\hline
\end{tabular}

Kampung Tua Tanjung Piayu Laut kini dihuni oleh masyarakat asli Kampung Tua Tanjung Piayu Laut dan masyarakat pendatang seperti Suku Batak, Suku Flores, Suku Bugis dan Suku Tionghoa. Sehingga kehidupan ekonomi masyarakat Kampung Tua Tanjung Piayu Laut sudah cukup maju. Hal ini dapat dilihat dari kehidupan ekonomi masyarakat yang sudah berkembang. Mata pencaharian masyarakat Kampung Tua Tanjung Piayu Laut sudah beraneka ragam selain menjadi nelayan terutama Rumah Makan seafood yang sekarang menjadi tempat tujuan wisata kuliner di Kota Batam. Selain itu juga ada juga yang bekerja ditempat industri atau perusahaan dan juga bekerja di restoran seafood milik masyarakat Kampung Tua Tanjung Piayu Laut yang berda di sekitar Kampung Tua Tanjung Piayu Laut. 


\section{B. Perkembangan Kampung Tua Tanjung Piayu Laut Tahun 2010-2016}

Kampung Tua Tanjung Piayu Laut sebagai Kampung Tua yang ada di Kota Batam dan sebagai tempat wisata kuliner di Kota Batam dari tahun ke tahun dibenahi dan dikembangan. Sejak tahun 2010 melakukan perbaikan dan penyempurnaan secara fisik yang meliputi: membuat jalan menuju Kampung Tua Tanjung Piayu Laut, menambah sarana transportasi untuk menuju Kampung Tua Tanjung Piayu, membenahi tempat wisata yang sudah ada di Kampung Tua Tanjung Piayu Laut.

Pada tahun 2011 sampai 2013 pemerintah melakukan proses peningkatan dibidang sarana dan fasilitas Kampung Tua Tanjung Piayu Laut. Pada tahun 2014 sampai 2015 pengembangan Kampung Tua Tanjung Piayu Laut mengalami perbaikan dan pemeliharaan yang sangat signifikan. Pada tahun 2016 pembangunan sarana dan prasarana Kampung Tua Tanjung Piayu Laut ditingkatkan dengan melebarkan jalan utama atau jalan besar menuju Kampung Tua Tanjung Piayu Laut.

\section{Perkembangan Kehidupan Ekonomi Masyarakat Kampung Tua Tanjung Piayu Laut Sebagai Tempat Wisata Kuliner di Kota Batam}

Perkembangan Kampung Tua Tanjung Piayu Laut sebagai tempat wisata kuliner di Kota Batam juga berpengaruh terhadap perkembangan kehidupan ekonomi masyarakat. Salah satunya adalah membuka peluang bagi masyarkat sekitar.

\section{Mata Pencaharian}

Dahulu mata pencaharian masyarkat Kampung Tua Tanjung Piayu Laut adalah sebagai nelayan. Mereka sangat mengandalkan laut sebagai pemenuh kebutuhan hidup sehari-hari. Seiring berkembangnya zaman maka mata pencaharian masyarakat Kampung Tua Tanjung Piayu Laut mengalami perubahan mereka tidak hanya mengandalkan laut sebagai pemenuhan kebutuhan hidup sehari-harinya. Masyarakat Kampung Tua Tanjung Piayu Laut mulai banyak yang bekerja di perusahaan dan berjualan di sekitar Kampung Tua Tanjung Piayu Laut.

\section{Pendapatan}


Sebelum adanya rumah makan seafood masyarakat Kampung TuaTanjung Piayu Laut pendapatannya tidak menentu tergantung dengan hasil tangkapan yang diperoleh dari laut. Sekarang ini berbeda nelayan bisa menjualnya ke rumah makan seafood dengan harga yang lumayan. Biasanya ada juga yang bekerja untuk rumah makan seafood itu sendiri. Sehingga jika pendapatan dilaut sedikit maka pendapat lain bisa mencukupi.

\section{Hambatan Yang Di Hadapi Pelaku Wisata Kuliner Di Kampung Tua Tanjung Piayu Laut}

Pelaku wisata kuliner di Kampung Tua Tanjung Piayu Laut menemui bebeberapa kendala yang mereka hadapi. Akan tetapi mereka berusaha untuk mencari solusi agar kendala yang mereka hadapai tidak begitu berdampak besar terhadap yang dihasilkannya dan mereka pun dibantu oleh masyarakat sekitar dalam menanganinya.

Adapun kendala-kendala yang dihadapi para pelaku wisata kuliner menurut penelitian peneliti antara lain: kurangnya modal yang dimiliki pelaku wisata kuliner untuk mengembangkan hasil karyanya atau produksinya agar dapat mengikuti perkembangan, musim yang dimaksud disini adalah antara musim libur dan musim biasa, letak yang terkadang sulit ditemukan para wisatawan yang dikarenakan tempat sulit dijangkau atau terlalu masuk kedalam perkampungan, Tidak adanya ketersediaan air bersih.

\section{E. Pembahasan}

Keberadaan rumah makan seafood sangat membantu nelayan dalam menjual hasil tangkapan dari pada sebelumnya, kemudian juga menunjukan semakin adanya kemudahan aktifitas perekenomian di Kampung Tua Tanjung Piayu Laut. Dahulu mereka hanya mengenal teknologi sederhana dan mudah untuk berjualan seafood, saat ini mereka sudah mulai mengenal teknologi untuk meningkatkan jumlah penjualan dan pendapatan. Peningkatan permintaan rumah makan seafood sangat meningkat, dengan meningkatnya pendapatan nelayan ini 
pendidikan anak-anak mereka lebih baik hingga jenjang perguruan tinggi agar kehidupannya bisa lebih baik lagi.

Sekarang masyarkat Kampung Tua Tanjung Piayu Laut sudah banyak yang meninggalkan profesinya sebagai nelayan, karena perkembangan zaman juga masyarakat lebih banyak memilih pergi ke perusahaan yang sekarang ini jalur ke luar sudah bagus berbeda dengan dulu yang akses jalannya sangat susah untuk ditempuh oleh kendaraan. Sekarang ini kendaraan sudah sangat nyaman dan lancar untuk masuk ke Kampung Tua Tanjung Piayu Laut.

\section{KESIMPULAN DAN SARAN}

Kampung Tua Tanjung Piayu Laut adalah salah satu Kampung Tua di Kota Batam yang mempunyai banyak sekali potensi dan daya tarik wisata. Dapat dilihat dari banyak wisata yang terdapat di Kampung Tua Tanjung Piayu Laut yang sangat menarik dan sangat dikenal oleh para wisatawan. Beberapa contoh obyek wisata di Kampung Tua Tanjung Piayu Laut yang dapat dikunjungi dan sangat diminati adalah wisata alam, wisata sejarah, wisata budaya, wisata bahari dan salah satunya wisata kuliner.

Kampung Tua Tanjung Piayu Laut keberadaan wisata kuliner juga berperan dalam perkembangan industri pariwisata. Para pelaku wisata kuliner di Kampung Tua Tanjung Piayu Laut juga menghadapi kendala, jadi para pelaku wisata kuliner masih perlu melakukan perbaikan guna untuk meningkatkan mutu dan daya tarik supaya dapat mengikuti perkembangan zaman.

Perkembangan ekonomi masyarakat Kampung Tua Tanjung Piayu Laut saat ini sudah lumayan baik daripada sebelum adanya rumah makan seafood. Dengan adanya rumah makan seafood ini berdampak baik masyarakat sekitar terutama nelayan, dulunya nelayan terkadang mendapatkan penghasilan yang tidak menentu dengan adanya rumah makan seafood ini penghasilan yang didapat nelayan lumayan mencukupi untuk memenuhi kebutuhan sehari-harinya. 
Historia: Jurnal Program Studi Pendidikan Sejarah

Vol. 3 No. 2 (2018): 92-101

P-ISSN 2301-8305

E- ISSN 2599-0063

\section{Saran}

Untuk pelaku wisata kuliner di Kampung Tua Tanjung Piayu Laut antara lain:

1. Tetap melestarikan dan menjaga makanan khas Kampung Tua Tanjung Piayu Laut. Walaupun didalamnya sudah ada perkembangan.

2. Selalu menjaga kenyaman, kebersihan, keindahan dan keamaan kepada para wisatawan. 
Historia: Jurnal Program Studi Pendidikan Sejarah

Vol. 3 No. 2 (2018): 92-101

P-ISSN 2301-8305

E- ISSN 2599-0063

\section{REFERENSI}

Basrowi. 2005. Pengantar Sosiologi. Bogor: Ghalia Indonesia.

Basrowi, \& Juariyah, Siti. 2010. Analisis Kondisi Sosial Ekonomi dan Tingkat Pendidikan Masyarakat Desa Srigading, Kecamatan Labuhan Maringgai, Kabupaten Lampung Timur. Jurnal Ekonomi \& Pendidikan, 7. 58-81.

Dahlan, Ahmad dkk. 2014. Nong Isa. Batam: PT. Batam Link Publisher.

Daliman. 2012. Metode Penelitian Sejarah. Yogyakarta: Ombak.

Jhingan, M.L. 2007. Ekonomi Pembangunan dan Perencanaan. Jakarta: PT. RajaGrafindo Persada.

Supardan, Dadang. 2008. Pengantar Ilmu Sosial Sebuah Kajian Pendekatan Struktural. Jakarta: PT. Bumi Aksara.

Sutrisno, Edi dkk. 2007. 35 Tahun Otorita Batam. Batam: PT. Batam Link Publisher.

Yakub, Yubahar dkk. 2015. Mengenal Provinsi Kepulauan Riau. Batam: Bestko. 